$43(88 \%)$ of respondents wanted these topics to be covered during medical school. A recent survey of 56 UK paediatricians and general practitioners rated highly the importance of undergraduate knowledge of accident prevention $3.7 / 5$ and ability to engage in health promotion $4 / 5$.

Conclusions This study demonstrates a lack of confidence and competence among medical students to provide advice about child safety despite clinicians considering this topic essential to undergraduate knowledge. Efforts must be made to improve the quality of child safety and child health promotion advice given to parents and undergraduate training provides an ideal opportunity to develop these skills.

\section{G500(P) EARLY NUTRITION FOR LATER HEALTH: WHY 'EARLY' SHOULD START IN PREGNANCY}

J More. School of Health Professions, Plymouth University, Plymouth, UK

10.1136/archdischild-2015-308599.453

\section{Aims}

1. To research the evidence base underpinning the short and long term effects of nutritional status and insufficiency during fetal and infant life

2. To assess the knowledge base of healthcare professionals and the resources available to them and parents to optimise nutritional advice for families during this key developmental period

\section{Methods}

1. An extensive literature search and interviews with key experts in the field

2. Qualitative and quantitative surveys of 150 healthcare professionals and 1,000 mothers/mothers-to-be to understand perceptions/attitudes and the level of knowledge about the impact of nutrition and lifestyle during preconception, pregnancy, infancy and the preschool years on health outcomes.

Results

- Maternal nutritional status and BMI during preconception and pregnancy impacts on programming and development in the fetus, affecting short and long term health outcomes of mother and child

- Maternal obesity and excess gestational weight gain affects hormonal balance and increases risk of complications in pregnancy and obesity in the infant and childhood

- Maternal nutritional status and type of infant feeding affects growth, bone health, risk of some infections and atopic disease in children with a family history of allergy

- Knowledge base and training of some HCPs is inadequate and most would welcome more training and consultation time

- Weighing during pregnancy, calculating pre pregnancy BMI and advising on suitable gestational weight gain is not routine

- Advice on healthy eating and supplementation to ensure adequate intakes of folate, vitamin $\mathrm{D}$, iodine, iron and omega 3 during preconception and pregnancy is not routine

- Mothers would welcome more advice and support during preconception and, pregnancy and on early life nutrition

Conclusion Families need updated, consistent evidence based information on nutrition and weight management preconception, during pregnancy and early life and HCPs need more time, resources and training to effectively deliver this.
G501(P) TO ASSESS THE FUNCTIONAL STATUS, SOCIAL HABITS, AND WORRIES IN A GROUP OF UNACCOMPANIED REFUGEE AND ASYLUM-SEEKING MINORS AND THE IMPLICATIONS OF THESE ON HEALTH BEHAVIOUR AND MENTAL HEALTH

${ }^{1}$ A Woods, ${ }^{1,2} \mathrm{C}$ Wood, ${ }^{2} \mathrm{~T}$ Thomas, ${ }^{2} \mathrm{M}$ Abraham. ${ }^{1}$ St Georges University, London, UK ${ }^{2}$ Charitable Organisation, Caras/KKF, London, UK

\subsection{6/archdischild-2015-308599.454}

Method Unaccompanied minors used a colour sticker system to answer questions about their abilities, function, social habits and desires, and worries during contact sessions with local charity.

Results "I worry about....feeling sad all the time" $83 \%$ respondents

"I worry about....not being able to sleep" 92\% respondents

"I worry about....having nightmares" $66 \%$ respondents

"I worry about....the police" 50\% respondents

"I worry about....my health" 42\% respondents

$55 \%$ described difficulty accessing health services

$42 \%$ interviewed said that if they had a problem they would definitely share it with only 1 person, or no-one.

Conclusions The NHS is currently facing a crisis in providing mental health for young people-many young people with acute mental health needs are unable to access CAMHS beds in the wider area.

Our study has highlighted the potential for mental health problems in a group of young adults where 'feeling sad', 'nightmares' and 'not sleeping' are common occurrences. It is well documented that access to mental health services to asylum seekers during the resettlement period is very poor, however these unaccompanied minors are at further risk as they are on their own and often living with unknown adults and in undesirable accommodation. Protective factors to refugee/asylum seeking children have been documented as good settlement and social support in new country. However, for this specific group of children this is stability they often lack, putting them at further risk.

Studies and recent highly publicised reports have found that children in care are at higher risk of physical and sexual abuse and mental health problems, our study found that $16 \%$ would not feel comfortable sharing a problem with anyone, and a further $25 \%$ would only share it with 1 named role.

Ensuring a proactive approach to mental health in this community is key, small specialist organisations are vital for providing additional support to these unaccompanied minors, providing stability and facilitating positive, trusting relationships with adults.

\section{G502(P) RISK ASSESSMENT OF CHILDREN WITH EATING DISORDERS: A RETROSPECTIVE ANALYSIS OF INPATIENT ADMISSIONS}

C Swinburne. Paediatrics, University Hospital Crosshouse, NHS Ayrshire and Arran, Kilmarnock, UK

\subsection{6/archdischild-2015-308599.455}

Background In 2012 the Royal College of Psychiatrists published the Junior MARSIPAN guideline on the management of anorexia nervosa in patients under 18 years of age. A risk assessment framework was proposed at this time to aid identification of patients at risk of serious complications. 
Aim To evaluate current clinical practice, with a focus on risk assessment at time of admission, and to compare this with the risk assessment framework proposed by the Royal College of Psychiatrists.

Methods All patients with an eating disorder requiring paediatric inpatient admission were identified over the period of June 2009 to February 2014. A retrospective casenote analysis was performed and data extracted using a standard proforma. Initial assessment of each patient was reviewed for documentation of BMI, weight, cardiovascular health (heart rate, syncope, significant orthostatic changes, irregular heart rate), ECG abnormalities, hydration status, temperature, biochemical abnormalities, disordered eating behaviours, engagement with management plan, activity and exercise, muscular weakness, self-harm/suicide, other mental health diagnoses as well as other potential co-existing risk factors.

Results A total of 14 patients were identified with 22 admissions over the data collection period. 15 patients were admitted electively via the local CAMHS team, 4 patients via A\&E and 3 patients following GP referral. No patients had a formal risk assessment performed. Assessment performed at the time of admission was highly variable. With the information available 10 patients were categorised as high risk, 11 patients were categorised as alert to high concern, and 1 admission was categorised as moderate risk. No patients were classified as low risk.

Conclusion This study highlighted the fact that children with eating disorders are treated in paediatric inpatient wards as well as in specialist centres. Admissions to the paediatric wards are infrequent. Initial assessment and investigation of this patient group is highly variable and does not adhere to current guidance. Implementation of a formal risk assessment framework is required in order to identify patients at risk of complications. The development of specific admission documentation based on Royal College guidance would aid assessment and help guide inpatient management, thereby providing a more consistent approach to patient care.

\section{G503(P) A 3 YEAR STUDY OF PAEDIATRIC MENTAL HEALTH ADMISSIONS TO A GENERAL PAEDIATRIC WARD}

N Johnson, H Massey, L White. Department of Paediatrics, Hinchingbrooke Hospital, Huntingdon, UK

\subsection{6/archdischild-2015-308599.456}

Aims The increasing prevalence of mental health problems is a well-recognised phenomenon in the paediatric population. While there are reviews of presentations to accident and emergency and to in-patient psychiatric hospitals, there are few studies of child mental health admissions to a general paediatric ward. The aim of this study was to investigate the prevalence of mental health conditions on a general medical paediatric ward and care pathways once admitted.

Method A retrospective case note study was performed of all cases admitted to a general paediatric ward between March 2011 and March 2014 in a district general hospital that required psychiatric review. Time of presentation, reason for presentation and admission, waiting time for psychiatric review, outcome of review and length of stay were all recorded, as well as the mental health background of those who presented.

Results 201 cases were identified, the youngest was 9 years old the median age was 15 years. Mental health admissions have increased from 38 between March 2011 and February 2012 to 93 from March 2013 to February 2014. The most common

\section{REASON FOR PRESENTATION}
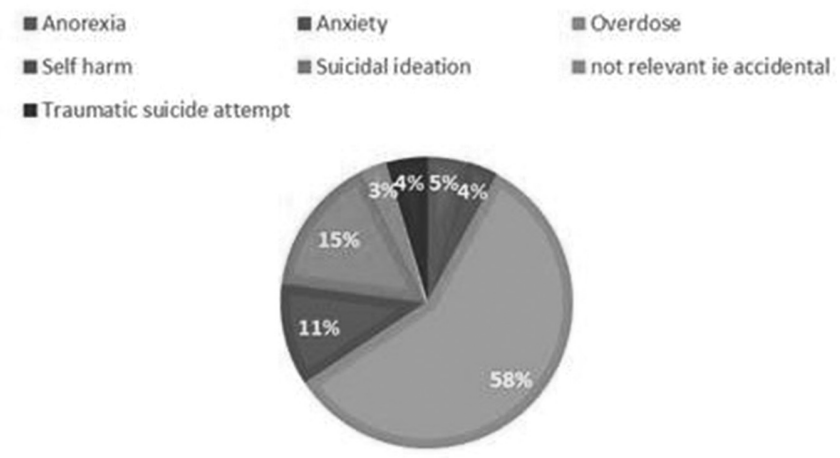

Abstract G503(P) Figure 1

reason for presentation (58\%) was overdose, followed by suicidal ideation (15\%) and self-harm (11\%), (Figure 1). Sixty percent of these admissions occur out of hours. $76 \%$ of children who present are already known to the Child And Adolescent Mental Health Service (CAMH). Of children admitted to the ward $49 \%$ required CAMH review only. Of these reviews, $16 \%$ occurred the same day as admission, 51\% the following day and $6 \%$ waited more than a day for review. The most common outcome of review was discharge with $\mathrm{CAMH}$ follow up as an outpatient $(73 \%)$

Conclusion Mental health admissions to the general paediatric ward increased in our population, reflecting the national trend. Most of these admissions occurred out of hours when there is no specialist child mental health cover. As a consequence of this most children did not see a physician with expertise in mental health on the day of admission. Most admissions were discharged with ongoing mental health follow up adding to the burden placed on CAMH.

\section{G504(P) BELOW THE TIP OF THE ICEBERG - LIFE BEFORE TIER 3. A STUDY OF MENTAL HEALTH PROVISION IN SCHOOLS}

S Sayani, M Blair. Child Public Health Team, Northwick Park Hospital, Northwest London Hospitals NHS Trust, Harrow, UK

10.1136/archdischild-2015-308599.457

Background Due to lack of funding in the local borough, there is no formal Tier 2 clinical CAMHS (Child and Adolescent Mental Health Services). Tier 3 CAMHS will see children with severe mental health disorders, however those that don't meet the thresholds have to be supported by schools, children's services and charitable organisations.

Aims To find out what type of mental health support is provided in schools and to understand schools perspectives on this topic.

Method All 48 state schools in the local borough were emailed an electronic survey. The survey requested quantitative and qualitative responses. Qualitative responses were analysed thematically.

Results 21/48 (44\%) schools responded. 90\% had a counselling service but $42 \%$ of service providers did not have mental health training. The most common problem encountered by services was Anxiety and Depression (89\%). 53\% of schools expressed difficulties with the onward referral process to Tier 3 CAMHS. $21 \%$ of schools mentioned concern with the level of skills within their own service including lack of diagnostic abilities, as well as 